niet werden gevonden, alsdan tot borge in handen van de Compagnie te stellen zullen de zoone van Biema ende de sone van Montemarano.

29.

De regeringe belooft aan de Compagnie uijt te keeren in vergoedinge van haare oncosten te oorloge $250.000 \mathrm{R}^{\text {rs }}$ invijff moussons, ${ }^{1}$ ) naest aan een volgende, 't zij in canon, 't zij in coopmanschappen, 't zij in gout, silver, off juwelen, elk na sijn waarde.

30.

Ende opdat alle de bovenstaande poincten des te religieuser mogen worden onderhouden, soo sijn de selve door den conink van Macasser en sijne hier onder geschreven Grooten, en bij wegen van de Compagnie door den Admiraal, nevens oock alle de coningen en princen in dit verbont begrepen, naar aanroepinge van des Heeren Heijligen naame beeedicht, geteeckent en verzegelt, elck op zijne wijse, in een velttent, op Vrijdagh den $18^{\text {en }}$ November 1667 , ontrent Borrombon op Compagnies eijgen gront.

\title{
CCCXVIII. MAKASSAR.
}

\section{9-31 Maart 1668. ${ }^{2}$ )}

Onder hen, welke in den strijd tegen de O. I. C. Makassars zijde waren blijven houden, waren de radja van Tello en de karaẽng Linques. ${ }^{3}$ ) De radja van Tello was ziek en teekende het Boengaaisch traktaat den 25 November 1667 niet. Ook de Karaẽng van Linques was of heette ziek (Stapel, passim; Dagh-Register 1668-1669, bldz. 77). Beide vorsten ,hadden een naerder contract mette Comp. ${ }^{e}$ gemaeckt ende hun daerbij op nieuw verbonden getrouw te sullen blijven ende gemelte Comp. ${ }^{e}$ voor haer beschermheer te erkennen". (Dagh-Register 1668-1669, bldz. 76 v.v.).

Naeder contrackten gemaakt met radia Tello $^{4}$ ) en crain Linques ${ }^{5}$ ) den $9^{\mathrm{e}}$ en $13^{\mathrm{e}}$ Maart $\mathrm{A}^{\circ} 1668$.

\footnotetext{
1) Vg1. Veth, Uit Oost en West, bldz. 23.

2) Uit het Contractboek. - Ook bij Valentijn, Macassaarsche Zaaken, bldz. 164 , v.v.

3) Beide worden in art. 26 van het Boengaaisch traktaat door Speelman gerekend onder de "Coningen uijt het midden van den raat".

4) Tello, een voormalig vorstendommetje ten noorden van Makassar (Gowa). Daarmede wordt het in de geschiedenis veelal verbonden, te meer daar het bestuur over beide rijken veelal dooréén liep.

5) Diens stamland lag ten Zuiden van Makassar. (Stapel, bldz. 175). Hij noemt zich zelf koning van "Chinrana (Tjenrana) Linques". Zie hierna het contract met Tjënrana.
} 
Ick, paducca siri sultan Haroumra ${ }^{1}$ ) Chijt, coningh van Tello, $\mathrm{nu}$ in de laast gemaackte vrede met Macassar ${ }^{2}$ ) gewerden zijnde Compagnies vrunt en bontgenoot, gelijk daarvan het gemaackte ende door ons beeedige contrackt in 't breede spreeckt, mij erinnerende de getrouheijt en vaderlijcke zorge, waar met de Compagnie doorgaans en altoos is aangedaan over haare verbonde vrunden en bontgenoten, verklare door den desen, naar ingenomen advijs van mijne lantsheeren, broeders en onderdanen, te raade te zijn gewerden, mij ende mijne, oock nevens dien mijn gantsche rijcke en jurisdictie, noch nader en int bijsonder met deselve Compagnie te verbinden, en tevens te versoecken dat ik niet alleene in haare bescherminge particulierlijck aengenomen, neen maar oock mijne kinderen, soo bij mijn leeven als naar mijn doot, met mij aengesien mogten werden als ware vrunden en verwanten van de $\mathrm{E}$. Compagnie, die se hout en neempt in haare vaderlijcke bewaringe, opdat ons van niemande ter werelt eenigh leet of onrecht mogte overcomen, 't gunt den Heer Cornelis Speelman, admiraal van Compagnies magten alhier, representerende door craght van zijne commissie de hooge overheijt van den Gouverneur Generaal en Raaden van India op Batavia, te mijnen begeeren door paducca sirij sultan Mandarsaha, Coningh van Ternaten, ende Mamaliang, coningh van Linques, voor gedraagen en te kennen gegeven wezende, heeft het goedertierentlijcken en in een opregte herte believen aan te nemen, mits welcken ick mij, mijne kinderen, broeders en susters, voorts alle mijne rijcxheeren en onderdanen verbinde tot alle opregte getrouheijt, ons gehelijck overgevende aen de goede voorsorge van de Compagnie, alsoo dat haare vijanden en vrunden de mijne en onse, en wij altijt bereit zullen wesen, met en nevens haar, daarse ons comen te roepen, te oorlogh te trecken, gelijck dan oock mijne kinderen en kintskinderen in cas van mijn overlijden sullen staan en blijven onder haare vaderlijcke voogdije. En so der op mijn afsterven geen bij leven waaren of dat sijluijden stervende, geene naarlieten, sullen mijne lantsheeren, broeders en vrunden geenen coninck in mijner plaatse mogen verkiesen als ten overstaan en met goetvinden van de Compagnie. Ja, ingevalle oock sulcke mijne kinderen haar niet naar behooren quaamen te gedragen, sal de Compagnie ten goede van mijn landt en onderdanen oock ymant anders van de naaste in haare plaatse mogen stellen, 't geene ik alles uijt

\footnotetext{
1) Valentijn, bldz. 164: „Harroenarra”.

2) Het Boengaaisch tractaat.
} 
opregte herte de Compagnie toevertrouwe. Ende opdat hiervan voor de gantsche werelt blijcken meuge, soo heb ik desen door mijn Rijcxsegel versegelt, ende door dain ${ }^{1}$ ) Mangappa, mijn broeder, en Carre Motulle met galleran ${ }^{2}$ ) Care Pato laten onderteijckenen; oock de getrouwe onderhoudinge van dien op den Alcoran naer onse wijse ten bijwesen van de Monsieurs Danckert van der Straaten, oppercoopman, Pierre Dupon, capiteijn en Abraham Gabbema, fiscaal, Lesworen, sullende, als het des admiraels begeeren en goetvinden sal wesen, desen in mijn stadt en plaatse door openbare gomslagh verkondigt. Aldus gedaan, besworen en versegelt in mijn fort genaempt Tello op den $25^{\mathrm{e}}$ van de maant Ramelan ${ }^{3}$ ) des jaars 1078, sijnde volgens de Nederlantse stijl den 9e Maart 1668, wesende hier over tot getuijge beroepen den hoogstgeboorenen groot mogenden Mandarsaha, coningh van Ternata, en mijnen bloetverwant Mamalijanij, coningh van Linques, die tot betijckeninge van dien mede haar zegel hier onder gestelt hebben.

Wij, zijnde geweest expres gecommitteert door den Heere admiraal Cornelis Speelman, verclaaren dat in onze presentie ter plaatse voornoempt alsodanig desen contracte is solemnelijk self oock door de Coning en getuijgen op den Alcoran beeedicht en verseegelt, het selve al te voren duijdelijck begreepen en grondelijck verstaan, gelijck wij het dan oock aan welgemelde sijn E. in dier voegen gerapporteert hebben, en oversulcx g'ordonneert, zij Compagnies zegel hier nevens te stellen, met onderschrijvinge van den Secretaris ten dage en jare als booven. In 't casteel Rotterdam op Maccassar. Was geteijkent: Danckert van der Straaten, Pierre Dupon, A. Gabbema. Ter zijde stondt Compagnies zegel gedruckt in rooden lacke, waaronder geschreven stont: ter ordonnantie van den Heer Admiraal voornoemt, ten dage en plaatse gemelt, en was geteijckent Hendrick Louff, Secretaris.

Ick Mamalijanij, erffconingh van Chinrana Linques etc ${ }^{\mathbf{a}}$, vrijheer in 't coninckrijck van Maccassar, met rijpe aandagt wel en ter degen opgemerckt, gelesen en begrepen hebbende het geannexeerde contract, waar met te mijnen eijgen overstaan mijnen broeder, den coning

1) Daëng, een hoofd van lageren rang dan de karaëngs (Encyclopaedie), I, bldz. 8).

2) Glarang: een inlandsch ambtenaar. (Encyclopaedie, IV, bldz. 364).

3) Ramadhân. 
van Tello, sich aen de Compagnie heeft verbonden, verclare voor mij en alle mijne soonen en dogteren, huijsgenoten, landen ende volcken mij niet alleene mede sodanigh te verbinden, maar oock in 't geheel te stellen onder de gehoorsaamheijt ende de bescherminge van d'E. Compagnie, die ick belove in alle haare beveelens, diensten en ordonnantien nu en altoos in der eeuwigheijt gehou en getrou te wesen, oversulcx tot beteijckinge van waaragtige waarheijt en mijne sincere goede meijninge, hebbe ik desen, houdende het contract van Tello, voor hier in geinsereert, met mijnen sone genaampt Tahara $\mathrm{Crani}^{\mathbf{1}}$ ) van Pateena ${ }^{2}$ ) in handen van den admiraal beswooren, versegelt en onderteijckent, mede ten bijwesen van Danckert van der Straaten, oppercoopman, Pierre Dupon, capitaijn, Abraham Gabbema, fiscaal ; sijnde hier over getuijge alle bontgenoten, coningen, van wiens wegen haer zegels en hantteeckeningen hier onder gestelt hebben; den groot magtigen coning van Ternata, de coning van Pallaca en prince Calamatta, ende den coningh van Laijo. Op den $13^{\mathrm{e}}$ van de maent Maert 1668, zijnde naar onse reeckeninge den $29^{\mathrm{e}}$ van de maent Ramelan des jaers 1078, int casteel Rotterdam op Macassar. Onderstonden de zegels van de coningen van Ternata en Pallacca in rooden lack gedruct. Lager stont: nota dese besegelinge en onderteeckeninge van bovenstaande is eerst in vollen Rade den $31^{\mathrm{e}}$ Maart geschiet. Was geteijkent Danckert van der Straaten, Pierre Dupon, Abraham Gabbema. In margine stont Compagnies zegel in rooden lack gedruckt. Daar onder stont: Ter ordonnantie van E. Heer Admiraal ten dage en plaatse voornoempt en was geteijckent Hendrick Louff, Secretaris.

\section{SUMATRA'S WESTKUST-ATJEH.}

\section{April $1668 .^{3}$ )}

Pits maakte een voordeelig gebruik van de opdracht door den vorst van Minangkabau aan hem gegeven om dezen op Sumatra's Westkust te vertegenwoordigen, waardoor hij was geworden diens ,gemachtighde oprechtelycken aan den gantschen zeekant. Ende daerom soo draeght hij oock d: teijckenen van mijn groodtheijt" - schrijft den vorst van Minangkabau aar

\footnotetext{
1) Karaëng? Valentijn heeft ook „Crani” en niet: „Crain”.

2)?

3) Uit het Contractboek. - Ook in de onuitgegeven Oz'ergckoncn brici'cn en papieren van 1669.
} 